\title{
Development of an Improved Biodiesel Plant
}

\author{
C. N. Nwogu ${ }^{1}$, A. I. Obi ${ }^{2}$ \\ ${ }^{1,2}$ Department of Mechanical Engineering, Michael Okpara University of Agriculture Umudike, Abia State
}

\begin{abstract}
An improved biodiesel plant consisting of an oil tank, reaction chamber, centrifuge, evaporation tank and reservoir tank was designed, fabricated and evaluated. The developed plant produces biodiesel from used cooking oil obtained from restaurants, fast foods and hotels. The results of its performance test indicated $13.93 \mathrm{~kg} / \mathrm{hr}$ and $82.68 \%$ as the throughput and efficiency respectively. All materials used for the fabrication were sourced locally. The adoption and commercialization of the plant will help preserve Nigeria's ever depleting petroleum reserve as well as reduce environmental pollution caused by inappropriate disposal of used cooking oil.
\end{abstract}

Keywords: Biodiesel, Plant, Used cooking oil, Performance test, Improved

\section{Background}

In any nation, energy is the most fundamental requirement for human existence and activities(Ribeiro et al, 2011). Since the late nineteenth century, petroleum which is produced from crude oil has been the major source of energy for the world. Frequent hiking of oil prices, depletion of petroleum reserves and most importantly increasing environmental concerns create a need for a cleaner and renewable source of energy(Okoro et al, 2011). As a result, biodiesel is quickly becoming one of the fastest growing alternative fuels in the world due to its clean emissions profile, ease of use, and many other benefits (Ribeiro et al, 2011). Biodiesel is a renewable diesel fuel which can be produced by combining any natural oil or fat with methanol or ethanol by chemical means known as transesterification.

Biodiesel is a clean fuel because it only emits a little amount of Carbon dioxide into the atmosphere compared to fossil fuels(Okoro et al, 2011). Also it does not contain any sulphur and as such does not emit any dangerous oxides into the atmosphere when it burns. It has high combustion efficiency and high lubricity. It reduces engine wear thereby increasing the life of the fuel injection equipment (Emil et al, 2009).Biodiesel has a higher flash point of about $130^{\circ} \mathrm{C}$ compared to that of petroleum diesel which is about $64^{\circ} \mathrm{C}$. Hence it is less liable to explode than petroleum diesel making them safer to handle. The use of biodiesel does not require any modification of the diesel engine and can be used in pure form or blended with petroleum diesel at any level. Even a blend of $20 \%$ biodiesel and $80 \%$ petroleum diesel will significantly reduce carcinogenic emissions and gases that may contribute to global warming.

The primary raw materials (feedstock) used in the production of biodiesel are vegetable oils, animal fats and recycled greases (Gerpen et al, 2004). These materials contain triglycerides, free fatty acids and other contaminants. The vegetable oil referred to could either be edible (cooking oil) or non-edible vegetable oils like Jatropha and Algae.

The use of virgin (fresh) cooking oil will lead to the production of biodiesel whose cost would be about 1.5 times higher than the petroleum based ones. This problem can be controlled by using waste (used) cooking oil from kitchens, restaurants and canteens. Using waste cooking oil (WCO) as raw material will result in a biodiesel 2 to 3 times cheaper than those produced from fresh cooking oil (Samuel et al, 2013). According to Nada (2011), the production of biodiesel from (WCO) offers a triple-facetted solution: economic, environmental and waste management which is the primary aim of this work.

Every year, many millions of tons of waste cooking oil are generated worldwide. As at 2011, the United State of America with a population of about 300 million was producing in excess of 11 billion liters (2.9 billion US gallons) of recycled oil annually mainly from industrial deep fryers of potato processing plants, snack food factories and fast food restaurants. In the UK (population 63.9 million) 75,000 tons of waste vegetable oil arise from catering and industrial sources annually (Andrew S., 2003). Other countries like Germany and Brazil produce 600 million US gallons/annum and 3.2 million US gallons/annum respectively from $\mathrm{WCO}$ and other biodiesel feedstock. However, Nigeria with a population of over 165 million and an estimated national population growth rate of $5.7 \%$ per annum with hotels and fast foods situated almost in every corner in most cities and over $70 \%$ of its land mass suitable for arable farming, is producing less than 1,000 US gallons/annum (USEIA, 2012) mostly from laboratory practicals carried out in laboratories of various research institutes and tertiary institutions. This is because biodiesel production plants required to convert these WCOs into diesel are costly to import and maintain. A need therefore arises for the design and fabrication of such plant using local materials and indigenous technology. A typical biodiesel plant for producing biodiesel from $\mathrm{WCO}$ is illustrated diagrammatically in Figure 1. 


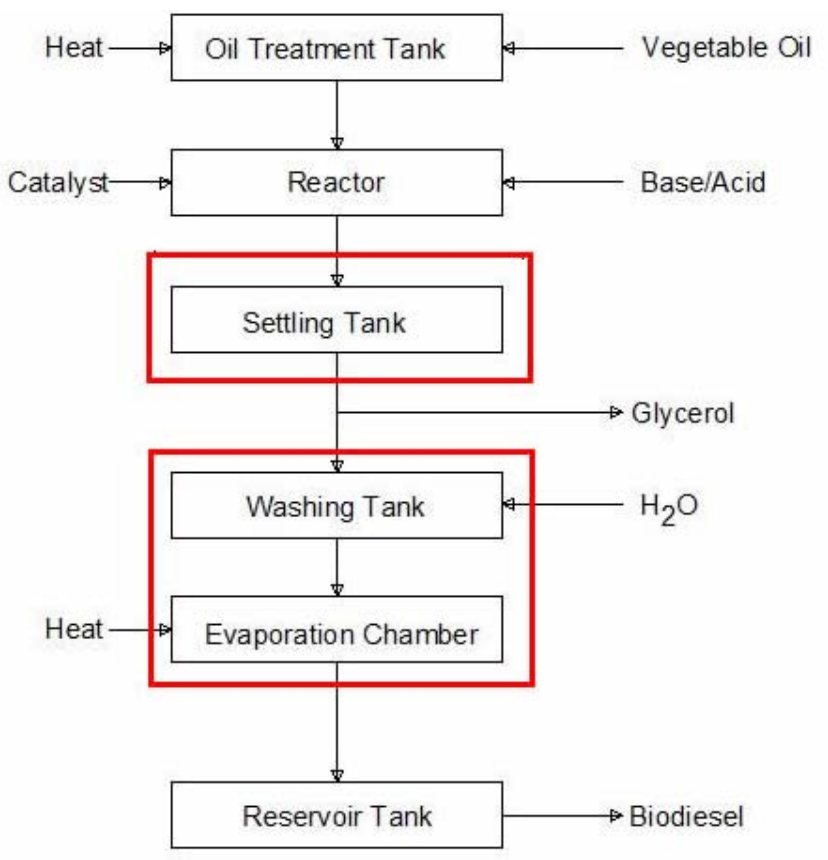

Figure 1: Batch Process biodiesel plant showing the bottle neck units

Using a settling tank to separate the methyl/ethyl esterglycerol mixture produced in the reactoris very time consuming (usually between 7 to 9 hours)and reduces the capacity of the biodiesel plant since the mixture must settle completely before the next operation can commence. Hence, the settling tank is replaced with a medium sized industrial centrifuge in the improved plant. Also, the improved plant was designed such that washing and evaporation can be achieved in one vessel. This will reduce the number of pumps in the plant thus, reducing its size and cost. The modified plant is shown in Figure 2 below.

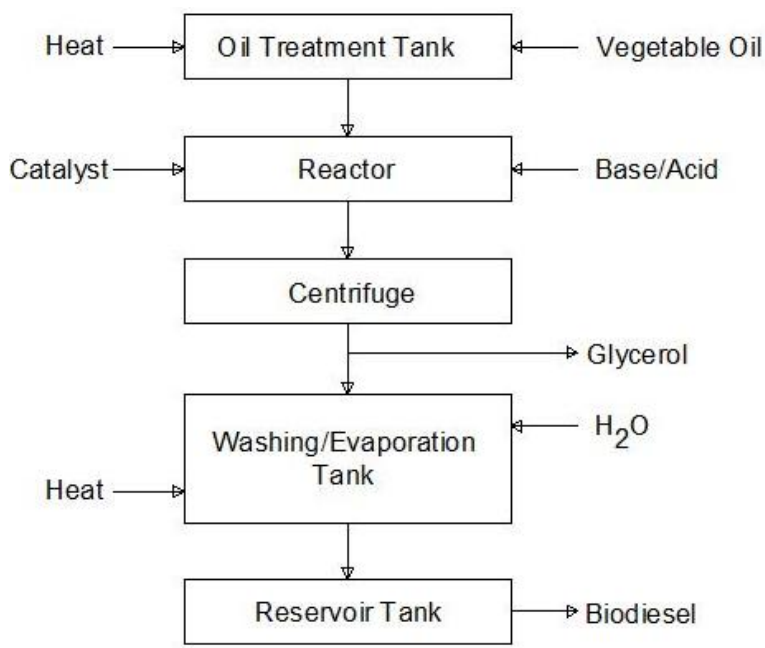

Figure 2: The improved biodiesel plant

\subsection{Objectives of the Study}

The main aim of this work is development and performance evaluation of an improved biodiesel production plant. Specific objectives include;

1) Design modification of existing biodiesel production plants by introducing a centrifuge for separating glycerol-methyl ester mixture and reduction in the number of pumps used in biodiesel production plants through achieving neutralization washing and drying of the methyl ester in one unit

2) Development of an improved biodiesel plantbased on the design modifications using locally sourced and standard materials.

3) Performance evaluation of the improved biodiesel plants.

\subsection{Justification}

The development of the plant will encourage the production of biodiesel in Nigeria, thus reducing dependency on our ever depleting fossil fuels and providing employment for our teeming youths. The biodiesel produced from this plant will be used in the country both as blend and substitute for petroleum based diesel, thereby reducing the pollution caused by the combustion of petroleum fuels, in line with the Federal Government's campaign for a "green environment".

\section{Materials and Methods}

\subsection{Design Concept and Considerations}

The design, material selection and development of the improved biodiesel plant were based on the following concepts and considerations:

1) Centrifuge was considered best for the separation of glycerol from methyl ester instead of sedimentation as in most existing systems to reduce production time and also achieve continuous production process.

2) Neutralization washing and evaporation processes were designed to occur in one vessel instead of two as in existing systems to reduce the number of pumps required in the plant.

3) The improved biodiesel plant design wasdeveloped using locally sourced standard materials to ensure low cost of production and maintenance of the plant.

\subsection{Selection of Pulleys and Belts}

The reactor and mixing vessel's stirrers are driven by two mild steel pulleys of $62 \mathrm{~mm}$ and $115 \mathrm{~mm}$ diameters respectively. These diameters were obtained using equation (1) (Khumi and Gupta 2005; Sharma and Aggarwal 2006).

$\frac{N_{2}}{N_{1}}=\frac{d_{1}}{d_{2}}$

Where:

$N_{l}=$ Speed of the driving pulley in r.p.m

$N_{2}=$ speed of the driven pulley in r.p.m

$d_{l}=$ diameter of the driving pulley

$d_{2}=$ diameter of the driven pulley

The design center distance between the two pulleys was calculated as $236.3 \mathrm{~mm}$ using equation (2)

$$
C=\frac{1.5 D_{2}}{(V R)^{1 / 3}}
$$

The minimum length of the belt required to drive the stirrers was obtained as $753.5 \mathrm{~mm}$ using equation (3) (Khumi and Gupta 2005; Sharma and Aggarwal 2006).

$$
L=2 C+1.57\left(D_{2}+D_{1}\right)+\frac{\left(D_{2}-D_{1}\right)^{2}}{4 C}
$$

\section{Volume 4 Issue 12, December 2015}




\section{International Journal of Science and Research (IJSR) \\ ISSN (Online): 2319-7064}

Index Copernicus Value (2013): 6.14 | Impact Factor (2014): 5.611

By assumption, the power transmitted by the belt drive should not exceed $3.75 \mathrm{KW}$. Hence, a "type A" V-belt with standard pitch length of $823 \mathrm{~mm}$ (IS: 2494 - 1974 standard) was selected for driving the stirrers. The actual center distance between the driving and driven pulleys of the stirrers was then obtained as $236.3 \mathrm{~mm}$ using equations (4), (5) and (6) (Khumi and Gupta 2005; Sharma and Aggarwal 2006).

$$
\begin{aligned}
& C=p+\sqrt{p^{2}-q} \\
& p=\frac{L}{4}-\frac{\pi}{8}\left(D_{2}+D_{1}\right) \\
& q=\frac{\left(D_{2}-D_{1}\right)^{2}}{8}
\end{aligned}
$$

The coefficient of friction $\mu$ between the pulley and the belt, maximum safe stress $\sigma$, cross sectional area a and weight per meter length of the belt was also determined from standard tables (IS: 2494 - 1974 standard) as $0.3,2.1 \mathrm{~N} / \mathrm{mm}^{2}, 81 \mathrm{~mm}^{2}$ and $1.06 \mathrm{~N}$ respectively (Khumi and Gupta 2005; Sharma

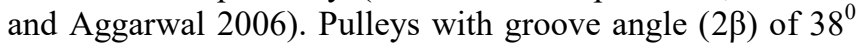
were selected for the drive due to its availability and cost effectiveness. The angle of contact of the driven pulley $\Theta$ is $197^{\circ}$ as shown in equation (7)

$$
\theta=180-2\left[\sin ^{-1}\left(\frac{D_{2}-D_{1}}{2 C}\right)\right]
$$

Tension in tight and slack sides of the belt $\left(\mathrm{T}_{1}\right.$ and $\left.\mathrm{T}_{2}\right)$ were determined as $134.53 \mathrm{~N}$ and 35.11 Nrespectively using equations (8) to (12) (Burr and Cheatham 2002; Khumi and Gupta 2005; Sharma and Aggarwal 2006).

$$
\begin{gathered}
T_{1}=T_{\max }-T_{c} \\
T_{\max }=\sigma \times a \\
T_{c}=m v^{2} \\
\frac{T_{1}}{T_{2}}=e^{\mu e \theta} \\
\mu e=\frac{\mu}{\sin ^{\beta} / 2}
\end{gathered}
$$

Where:

$\mathrm{T}_{\max }=$ maximum tension on the belt

$\mathrm{T}_{\mathrm{c}}=$ centrifugal tension on the belt

\subsection{Selection of Pumps}

The flow rates $(\mathrm{Q})$ at the reactor, centrifuge and evaporator pumps suction pipes were determined as $0.0024 \mathrm{~m}^{3} / \mathrm{s}$, $0.0017 \mathrm{~m}^{3} / \mathrm{s}$ and $0.0019 \mathrm{~m}^{3} / \mathrm{s}$ respectively, using equation (13) - (15) (Earle, 1983; Rajput, 2000).

$$
\begin{aligned}
& Q=V A \\
& V=\sqrt{2 g Z} \\
& A=\pi r^{2}
\end{aligned}
$$

Where:

$\mathrm{V}=$ velocity of flow

$\mathrm{A}=$ cross sectional area of pipe

$\mathrm{Z}=$ head of fluid above the nozzle

$\mathrm{g}=$ acceleration due to gravity $=9.81 \mathrm{~m} / \mathrm{s}^{2}$

$\mathrm{r}=$ radius of pipe

The static heads $\left(H_{S}\right)$ of the reactor, centrifuge and evaporator pumps were obtained as $650 \mathrm{~mm}, 140 \mathrm{~mm}$ and $1000 \mathrm{~mm}$ respectively using equation (16).

$$
H_{S}=H_{2}-H_{1}
$$

Where:

$\mathrm{H}_{2}$ = height of discharge pipe fluid surface
$H_{l}=$ height of suction pipe fluid surface

The friction head losses of the reactor, centrifuge and evaporator pumps were determined as $690 \mathrm{~mm}, 860 \mathrm{~mm}$ and $740 \mathrm{~mm}$ respectively using equation (17).

$$
H_{f}=f \times \frac{l}{D} \times \frac{v^{2}}{2 g}
$$

Where:

$l=$ length of pipe

$D=$ diameter of pipe

$f$ is a constant ranging from 0.01 to 0.04

The total pressure heads of the reactor, centrifuge and evaporator pumps were calculated as the sum of the respective static heads and the corresponding friction heads (Earle, 1983). Thus; the total pressure heads of the three respective pumps were determined as $1.34 \mathrm{~m}, 1.0 \mathrm{~m}$ and $1.74 \mathrm{~m}$ respectively.

Based on these determined pump parameters, $3 \mathrm{~m}$ head and $0.12 \mathrm{hp}$ rating pump was selected as the reactor, centrifuge and evaporator pumps respectively.

\subsection{Efficiency of the Plant}

The efficiency of the improved biodiesel production plant is expressed mathematically as shown in equation (18) below:

$\eta=\frac{\text { Power Output }}{\text { Power Input }} \times 100 \%$

Where:

power Output $=$ Power Input - Power Loss

The plant's power input is the sum of power ratings of the reactor and centrifuge motors; reactor, centrifuge and evaporator pumps; and oil tank and evaporator heating elements. The power losses in the respective components were determined as $0.06 \mathrm{kw}, 0.521 \mathrm{kw}, 0.0065 \mathrm{kw}, 0.0014 \mathrm{kw}$, $0.1 \mathrm{kw}, 0.24 \mathrm{kw}$ and $0.24 \mathrm{kw}$ using equations (20) - (22).

$$
\begin{aligned}
& P_{L m}=P_{I}-P_{S} \\
& P_{L p}=\frac{w Q H}{1000},(k w) \\
& Q_{l}=\frac{K A \Delta T t_{e}}{\pi l}
\end{aligned}
$$

Where:

$P_{L m}=$ Power lost by electric motor

$P_{I}=$ Power input to the motor

$P_{S}=$ Power developed at the shaft

$P_{L p}=$ Power lost by pump

$W=$ Weight of liquid

$Q=$ Volume of liquid

$\mathrm{Q}_{l}=$ Heat loss of electric heater

$K=$ Thermal conductivity

$A=$ Heat transfer surface area

$\Delta T=$ Temperature difference across material

$t_{e}=$ Exposure time

$l=$ Thickness of material

Thus, the overall efficiency of the improved biodiesel production plant was determined as $82.68 \%$. 


\section{International Journal of Science and Research (IJSR) \\ ISSN (Online): 2319-7064 \\ Index Copernicus Value (2013): 6.14 | Impact Factor (2014): 5.611}

\subsection{Manufacturing Procedure of the Improved Biodiesel Production Plant}

The improved biodiesel production plant comprises of the following units: Oil tank, Reaction chamber, Centrifuge,
Evaporation tank and Reservoir tank. Figure 3 shows the isometric view of the plant with the units/components identified.

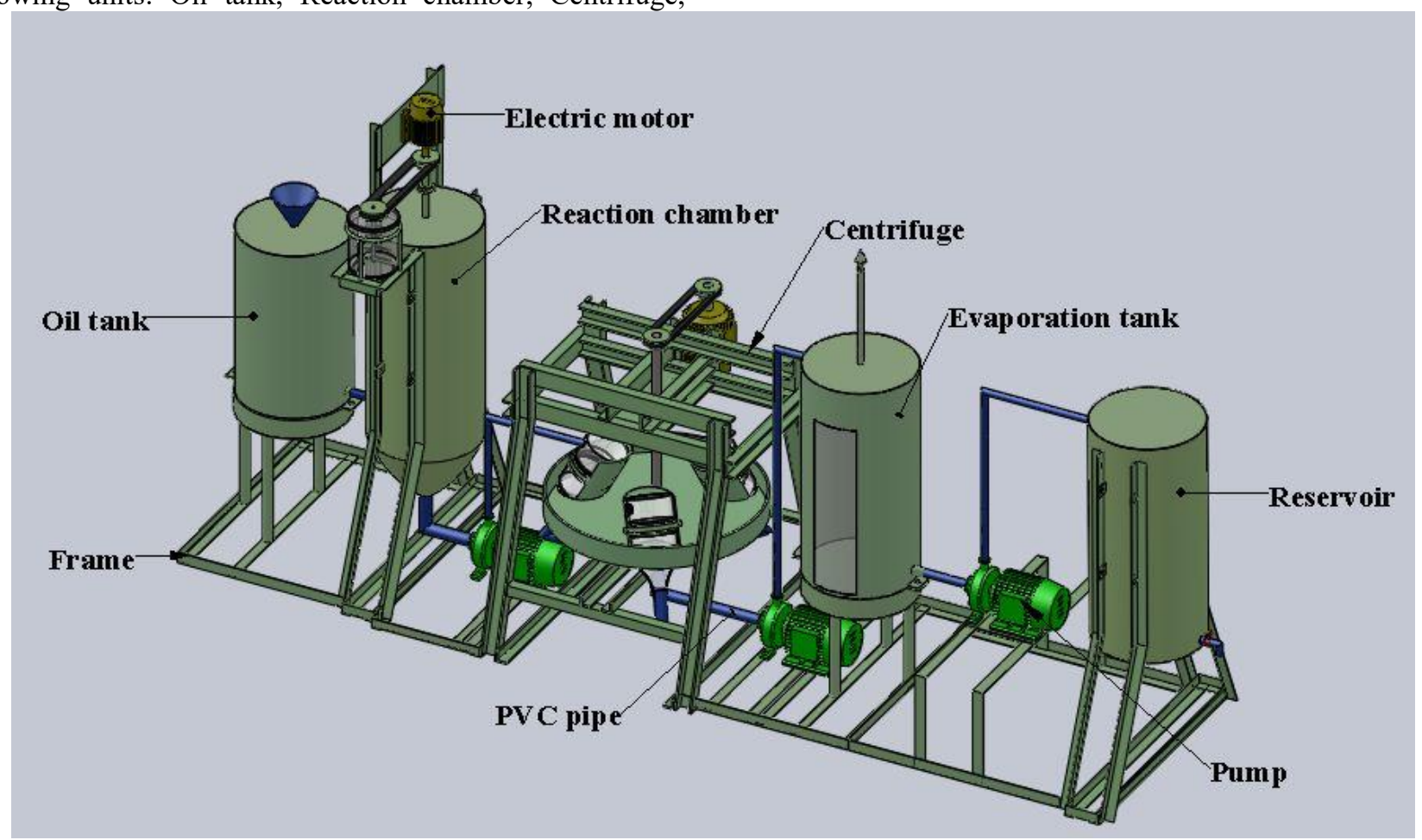

Figure 3: Isometric view of the plant

The frame is the main supporting structure upon which other components of this plant are mounted. It is a welded section constructed from a $5 \mathrm{~mm}$ thick mild steel angle bar except for the centrifuge whose frame was constructed using $8 \mathrm{~mm}$ thick mild steel U-channel (Nwogu, 2015).

Waste vegetable oils collected from kitchens, canteens, hotels and factories are poured into a $500 \mathrm{~mm}$ diameter oil tank of $800 \mathrm{~mm}$ length made from $3 \mathrm{~mm}$ thick mild steel plate. A hole of diameter $27.5 \mathrm{~mm}$ was drilled $20 \mathrm{~mm}$ from the base through which the oil flows into the reactor and an electric stove (heating element) fitted to the bottom.

The reaction chamber consist mainly of a reactorand a centrally mounted stirrer which is a $1400 \mathrm{~mm}$ long by $27 \mathrm{~mm}$ diameter mild steel shaft with several $120 \mathrm{~mm}$ long steel bars of $10 \mathrm{~mm}$ thickness welded to the surface. The space between two consecutive bars is $200 \mathrm{~mm}$. The reactor is a cylindrical tank of diameter $500 \mathrm{~mm}$ and length $1050 \mathrm{~mm}$, welded to a frustum of length $300 \mathrm{~mm}$, both made from $3 \mathrm{~mm}$ thick mild steel sheet. An electric motor is mounted centrally above the reactor. The motor rotates the stirrer by means of a coupling. The motor also turns a second smaller stirrer, mounted centrally with respect to a mixing vessel attached to the top left part of the reactor through a belt drive. The two stirrers rotate in opposite directions and a ratchet attached to the bigger stirrer prevents simultaneous rotation of the two stirrers. The forward and reverse motions of the electric motor is achieved through a circuit, designed to operate the single phase electric motor in Forward/Reverse direction.
The tapered bottom of the reactor is connected to a $46 \mathrm{~mm}$ diameter PVC pipe through which the transesterification reaction products are discharged into a centrifuge. After centrifugation, the glycerol which settles at the bottom of the centrifuge vessel is run off while the methyl ester (biodiesel) is pumped into an evaporation tank.

The evaporation tank is a cylindrical tank of diameter $500 \mathrm{~mm}$ with a height of $1000 \mathrm{~mm}$, made from $3 \mathrm{~mm}$ thick mild steel sheet. A slit $800 \mathrm{~mm}$ by $200 \mathrm{~mm}$ was cut longitudinally on one face of the tank and covered with a transparent plastic material to give a clear view of the content of the tank.

An electric stove (heater) is fitted beneath the tank for heating the liquid inside the tank. A $30 \mathrm{~mm}$ diameter hole was drilled $20 \mathrm{~mm}$ from the base of the tank for connection to a PVC pipe. The PVC pipe is connected to a pump which pumps the "clean" biodiesel obtained after washing and evaporation into a reservoir tank.

The reservoir tank is a $3 \mathrm{~mm}$ thick mild steel tank of $1050 \mathrm{~mm}$ length and $500 \mathrm{~mm}$ diameter. Four $5 \mathrm{~mm}$ thick mild steel bars of length $50 \mathrm{~mm}$ are welded to the surface (opposite each other) for mounting the tank to the frame. The reservoir tank stores the biodiesel after production.

\subsection{Performance Evaluation Procedure of the Improved Biodiesel Production Plant}

The improved biodiesel production plant was tested after fabrication to evaluate its performance. The test 


\section{International Journal of Science and Research (IJSR) \\ ISSN (Online): 2319-7064 \\ Index Copernicus Value (2013): 6.14 | Impact Factor (2014): 5.611}

performance indicators include; the conversion efficiency andthroughput.The conversion efficiency of the developed plant is the ratio of biodiesel yield to the quantity of WCO or other non-edible vegetable oil transesterified. It is expressed as a percentage. Throughput, TP is the ratio of the quantity of biodiesel collected from the plant to the time taken.

\section{Results and Discussion}

Table 1: Biodiesel yield from different transesterification reaction time

\begin{tabular}{|l|c|c|c|c|c|c|c|}
\hline Experimental Conditions & $1^{\mathrm{ST}} \mathrm{RUN}$ & $2^{\mathrm{ND}} \mathrm{RUN}$ & $3^{\mathrm{RD}}$ RUN & $4^{\text {th }}$ RUN & $5^{\text {th }}$ RUN & $6^{\text {th }}$ RUN & $7^{\text {th }}$ RUN \\
\hline KOH Concentration $(\mathrm{kg})$ & 0.2 & 0.2 & 0.2 & 0.2 & 0.2 & 0.2 & 0.2 \\
\hline Reaction Temperature $\left({ }^{0} \mathrm{C}\right)$ & 60 & 60 & 60 & 60 & 60 & 60 & 60 \\
\hline Reaction Time $(\mathrm{min})$ & 30 & 35 & 40 & 45 & 50 & 55 & 60 \\
\hline WCO quantity $(\mathrm{kg})$ & 40 & 40 & 40 & 40 & 40 & 40 & 40 \\
\hline Methanol Quantity $(\mathrm{kg})$ & 8 & 8 & 8 & 8 & 8 & 8 & 8 \\
\hline Biodiesel obtained $(\mathrm{kg})$ & 28.5 & 29.1 & 29.7 & 30.2 & 32.5 & 27.8 & 27.0 \\
\hline Glycerol obtained $(\mathrm{kg})$ & 13.8 & 13.1 & 12.8 & 12.7 & 12.7 & 12.3 & 11.9 \\
\hline Losses $(\mathrm{kg})$ & 5.9 & 6.0 & 5.7 & 5.3 & 3.0 & 8.1 & 9.3 \\
\hline
\end{tabular}

Highest biodiesel yield of $32.5 \mathrm{~kg}$ was obtained from the reaction that lasted 50mins (Table 1). Losses were recorded in each experimental run due to some unreacted alcohol, residual catalyst and emulsion removed during the washing stage of the production process. Similar observation was

\subsection{Effect of Transesterification Reaction Time on Biodiesel Yield}

Seven different samples of used vegetable oil, methanol and Sodium hydroxide were mixed in the reactor for periods of $30,35,40,45,50,55$ and 60 minutes respectively, representing seven batches of experimental runs. The effect of transesterification reaction time on biodiesel yield was determined from Table 1.

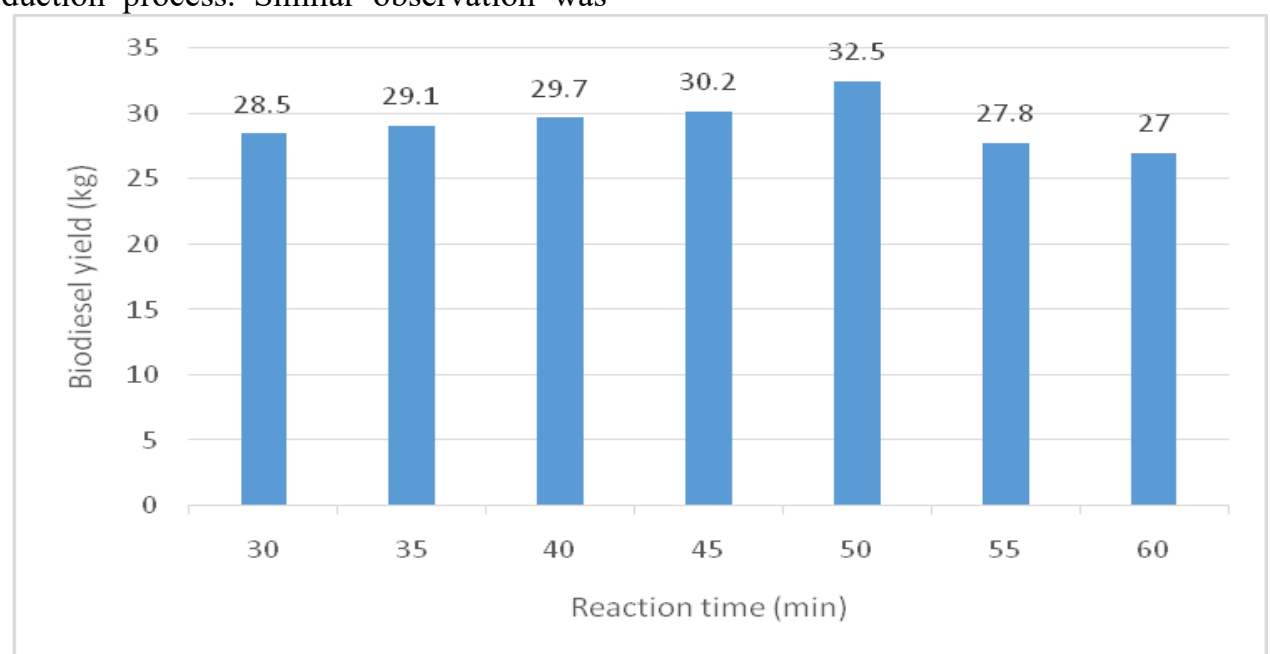

Figure 4: Biodiesel yields for different reaction times

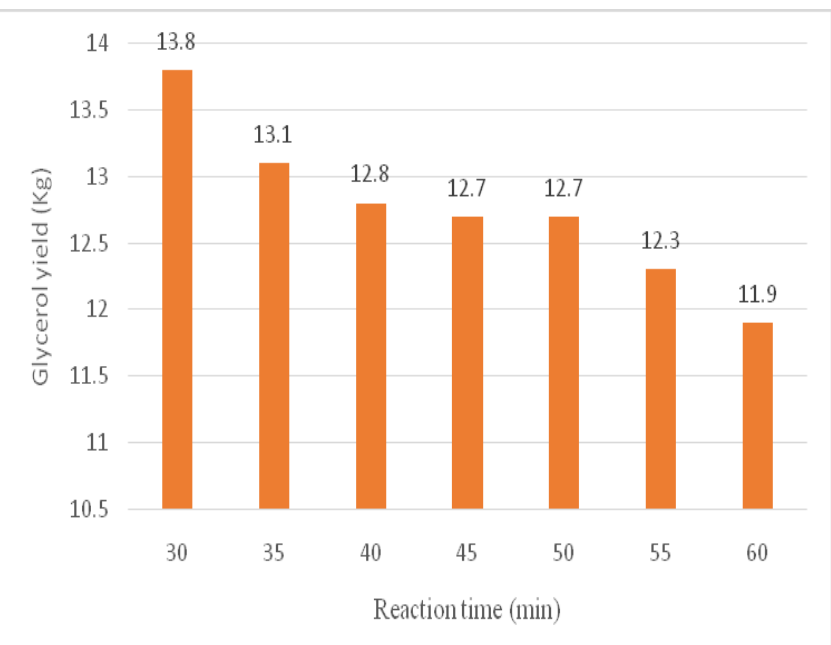

Figure 4 shows that biodiesel yield increases as reaction time increases until optimum biodiesel yield of $32.5 \mathrm{~kg}$ is obtained from the transesterification reaction which was allowed to last for 50 minutes. If the reaction is allowed to last beyond 50minutes, there will be a reduction in the quantity of biodiesel produced. Hence for optimum biodiesel yield, the reaction time is 50 minutes.

Figure 5 shows the result of plotting glycerol yield $(\mathrm{kg})$ against reaction time (mins). It can be seen from the chart that at reaction time of 30 minutes, the highest quantity of glycerol $(13.8 \mathrm{~kg})$ was produced while at reaction time of 60 minutes, the lowest quantity of glycerol $(11.9 \mathrm{~kg})$ was produced.

Figure 5: Quantity of glycerol produced for different reaction times

Volume 4 Issue 12, December 2015 


\section{International Journal of Science and Research (IJSR) \\ ISSN (Online): 2319-7064}

Index Copernicus Value (2013): 6.14 | Impact Factor (2014): 5.611

\subsection{Conversion Efficiency of the Plant}

As shown in Table 1, 40kg of WCO undergoes transesterification reaction to yield $32.5 \mathrm{~kg}$ of biodiesel. Hence, the conversion efficiency of the developed biodiesel plant was determined as $81.25 \%$ using equation (24).

$$
\frac{\text { Biodiesel yield }(\mathrm{Kg})}{\text { WCo quantity }(\mathrm{Kg})} \times 100 \%
$$

\subsection{Determination of Throughput of the Plant}

The total time consumed by the plant in producing a batch of Biodiesel is summarized in Table 2 below.

Table 2: Time required for each unit operation of the plant

\begin{tabular}{|c|c|}
\hline OPERATION & TIME (min) \\
\hline Pre-heating & 5 \\
\hline Transesterification reaction & 50 \\
\hline Separation & 40 \\
\hline Washing & 30 \\
\hline Pumping operations & 10 \\
\hline Intermediate operations & 5 \\
\hline & $\mathbf{1 4 0}$ \\
\hline
\end{tabular}

From table 2, it can be seen that the total time required to produce a batch of biodiesel is 140 minutes. The throughput (TP) of the plant was then determined as $13.93 \mathrm{~kg} / \mathrm{hr}$ using equation (25).

$$
T P=\frac{M}{t}
$$

Where:

$M=$ Mass of the Biodiesel produced by the plant $=32.5 \mathrm{~kg}$

$T=$ Total production time $=140$ minutes

\section{Conclusion}

The performance test of the improved biodiesel production plant showed that the plant has a throughput and efficiency of $13.93 \mathrm{~kg} / \mathrm{hr}$ and $82.68 \%$ respectively. The oil to diesel conversion efficiency of the plant was determined as $81.25 \%$ while the total cycle time to produce one batch of biodiesel is 140 minutes.

The developed plant will bring relief to the fuel industry since used vegetable oils which would have otherwise been disposed, causing environmental pollution will now be collected and processed into biodiesel. This innovation is expected to encourage some of the unemployed youths to engage in biodiesel production, thus, facilitating the achievement of MDGs/Federal Government Transformation Agenda with respect to job creation and use of energy from renewable sources.

\section{References}

[1] Andrew Stevens, (2003). Waste vegetable oil recycling for bio-diesel production in Essex and Cambridgeshire, waste WISE overview report.

[2] Burr, A. H. and Cheathan J. B., (2002). Mechanical Analyssis and Design (2 ${ }^{\text {nd }}$ edition) Prentice Hall Publishers, New Delhi.
[3] Chitra, P., Venkatachalam, P., and Sampathrajan, A., (2005). Optimization of experimental conditions for biodiesel production from alkali-catalyzed transesterification of jatropha curcus oil. Energy for Sustainable Development, Vol. IX, No. 3 pp. 13-18

[4] Earle R. L. (1983) Unit operations in food processing: Fluid flow theory. Published by NZIFST (Inc).

[5] Emil A., Z. Yaakob, S. K. Kamarudin, M. Ismail and J. Salimon, (2009). Characteristics and composition of jatropha curcas oil seed from Malaysia and its potential as biodiesel feedstock. Eur. J. Sci. Res, 29:396-403

[6] Gerpen J. V., Shanks B., and Pruszko R., (2004), Biodiesel Production Technology; Iowa State University, Subcontractor report, NREL/SR-510-36244, Pg 30-36.

[7] Khurmi R. S. and Gupta J. K. (2005). A Textbook of Machine Design (S. I. Units). Eurasis Publishing House (PVT) Limited, New Delhi-110 055

[8] Linus N. Okoro, Sedoo V. Belaboh, Nwakama R. Edoye and Bella Y. Makama, (2011) "Synthesis, Calorific and Viscometric Study of Groundnut Oil Biodiesel and Blends", Research Journal of Chemical Sciences ISSN 2231-606X.

[9] Nada E., M., Eisolh (2011), The manufacture of biodiesel from used vegetable oil. UNIKASSEL VERSITAT

[10] Nwogu C. (2015), Design and Development of an Industrial Centrifuge for Small and Medium Scaled Industries. Innovative Systems Design and Engineering, ISSN 2222-1727, Vol. 6 No 10.

[11]Rajput R. K. (2000). A Textbook of Fluid Mechanics and Hydraulic Machines (S. I. Units) S. Chand and Company LTD, Ram Nagar, New Delhi-110 055

[12] Ribeiro A., Casro F and Carvaiho J., (2011). Influence of Free Fatty Acid Content in Biodiesel Production on Non-Edible Oils Waste: Solutions, Treatments and Opportunities. $1^{\text {st }}$ international conference, $12^{\text {th }}-14^{\text {th }}$ September.

[13] Samuel O. D., Waheed M. A., Bolaji B. O. and Dario O. U. (2013), "Production of Biodiesel from Nigerian Restaurant Waste cooking oil using Blender", International Journal of Renewable Energy Research Vol. 3, No. 4.

[14] Sharma P. C. and Aggarwal D. K, (2006). Machine Design. S. K. Kataria and Sons, Nai Sarak Dechi. Katariabooks@yahoo.com.Pp19-58, 483-839

[15]USEIA (2012), Nigeria Biodiesel Production by year; Index Mundi http://www.indexmundi.com/energy.aspx (Accessed 2014). 